\title{
As Filosofias da matemática de Wittgenstein: Intensionalismo sistêmico e a aplicação de um novo método (sobre o desenvolvimento da filosofia da matemática de Wittgenstein)
}

Mauro L. Engelmann

UFMG

mauroengelmann@gmail.com

resumo Este ensaio visa estabelecer o intensionalismo (infinitos são dados por regras, e não por extensões) e a idéia de múltiplos sistemas matemáticos completos (várias "matemáticas") como as características centrais da filosofia da matemática de Wittgenstein. Tentaremos mostrar, em linhas gerais, como essas idéias surgem, como se relacionam, como progridem e, por fim, como são abandonadas em sua filosofia tardia. De acordo com o Tractatus Logico-Philosophicus, infinitos só podem ser dados por regras e existe um único sistema numérico (a essência do número consiste na idéia geral de ordenamento). 0 intensionalismo é mantido até pelos menos 1933, mas a idéia de sistema único é abandonada em 1929-30 (já nas Philosophische Bemerkungen). Em seu lugar entra em cena a ideia de múltiplos sistemas numéricos independentes e completos. Essa idéia determinará alguns desenvolvimentos na filosofia da matemática de Wittgenstein. A noção de "ver aspectos" do Big Typescript, por exemplo, surge para explicar a invenção de tais sistemas. A partir de 1934, contudo, Wittgenstein gradualmente abandona o intensionalismo e a idéia de múltiplos sistemas completos e independentes. Em sua filosofia tardia, ambas idéias são usadas apenas como instrumentos para dissolver a prosa filosófica sobre a matemática.

palavras-chave Wittgenstein; filosofia da matemática de Wittgenstein; período intermediário; intensionalismo; sistemas numéricos; multiplicidade de sistemas

\section{Introdução}

Gerrard ${ }^{1}$ diz que a filosofia da matemática de Wittgenstein caracteriza-se por ser um meio-termo entre a defesa metafísica da objetividade das Recebido em 9 de março de 2009. Aceito em 23 de agosto de 2009. doispontos, Curitiba, São Carlos, vol. 6, n. 2, p.165-184, outubro, 2009 
verdades matemáticas (platonismo de Frege e Hardy, por exemplo) e a negação desta objetividade (por exemplo, por parte do psicologismo lógico). A posição de Wittgenstein desenvolveu-se, de acordo com Gerrard, da seguinte maneira: "No período intermediário funda o significado no cálculo ele mesmo, no período tardio na práxis” (p. 175). Essa práxis é, por sua vez, fundada em contingências (regularidades empíricas) e, mais importante, em acordos em juízos (ou forma de vida). Fora dessa praxis não há significado (p. 191).

A interpretação de Gerrard parece-me incorreta de dois modos. Primeiro, em sua explicação da desistência de Wittgenstein da idéia de que o cálculo é a fundação do significado. Gerrard crê que a desistência se dá devido ao que considera uma implausibilidade implicada pela concepção wittgensteiniana: se são somente as regras do cálculo que fundamentam o significado, da mesma maneira que as regras fundamentam o jogo de xadrez, o que se jogava antes e depois da invenção da regra "en passant", por exemplo, não seria o mesmo jogo. Isso lhe parece absurdo. Ocorre, no entanto, que Wittgenstein não considerava isso absurdo. No Big Typescript (a partir de agora BT), por exemplo, nos diz que existem duas maneiras de vermos o catálogo de regras: ou como um "catálogo de regras determinado" (digamos, o catálogo de regras do xadrez de hoje) ou como "um catálogo variável de regras" ("o substrato de um determinado desenvolvimento histórico”) (BT 758; escrito originalmente no MS 113 p. 134r da primeira metade de 1932; também em Philosophische Grammatik (PG) p. 477). Wittgenstein, nesta passagem, alerta que a falta de atenção a esta distinção leva a confusões no caso de "número". Parece-me, assim, pouco plausível que Wittgenstein não estivesse deliberadamente, conscientemente, usando a palavra "cálculo" ou "sistema numérico" no sentido de um conjunto de regras.

A segunda dificuldade na interpretação de Gerrard expressa-se na tese de que em todo período intermediário e no período tardio o fundamental na filosofia da matemática de Wittgenstein foi a defesa de uma alternativa (meio-termo) entre a defesa metafísica da objetividade das verdades matemáticas e sua negação. Creio que Gerrard subestima a radicalidade com que Wittgenstein trata de problemas filosóficos e da seriedade de Wittgenstein em não defender teses filosóficas (disso trato na parte 4 desta apresentação). Se Gerrard estivesse certo, Wittgenstein teria 
defendido durante todo o período intermediário e tardio duas variações da mesma tese filosófica.

No que se segue, não tentarei mostrar em detalhes por que a interpretação de Gerrard é incorreta. Apresentarei, contudo, uma alternativa que deve se mostrar mais plausível do que a sua. Este ensaio tem quatro partes, sendo cada uma uma hipótese interpretativa de um dado período da filosofia da matemática de Wittgenswtein. Na primeira, tentarei mostrar que duas das idéias centrais do esboço de filosofia da matemática do Tractatus Logico-Philosophicus (T) são a idéia de que o infinito é dado por uma regra (intensionalismo) e a idéia de que existe um único sistema numérico (a essência do número consiste na idéia geral de ordenamento). Na segunda, sugiro que o intensionalismo é mantido até pelos menos 1933. No entanto, a idéia de sistema único é abandonada já em 1929-30 (nas Philosophische Bemerkungen (PB)). Em seu lugar entra em cena a idéia de múltiplos sistemas numéricos independentes e completos. Na terceira parte, sugiro que a introdução do famoso jargão wittgensteiniano de "ver aspectos" surge na filosofia de Wittgenstein para tratar de dois problemas relacionados à idéia de múltiplos sistemas completos e independentes (refiro-me ao problema de como passamos de um sistema a outro invenção de novos sistemas - e ao problema de sentenças matemáticas que estão fora de sistemas e parecem fazer sentido como, por exemplo, a equação de Fermat; o segundo já encontra uma solução parcial nas PB).

$\mathrm{Na}$ última parte deste ensaio (parte 4) aponto para uma mudança de postura na filosofia de Wittgenstein depois de 1934: o abandono da defesa do intensionalismo e da idéia de sistemas múltiplos. Ambas idéias são usadas por Wittgenstein apenas como instrumentos de oposição: a concepção extensional e a concepção intensional, sugere Wittgenstein, são ambas frutos de falsas analogias e hipóteses filosóficas duvidosas. Esse abandono deve-se ao uso do método que eu chamo "genético". ${ }^{2}$ Esse método já é constantemente empregado no Big Typescript (BT) de 1933, mas é somente a partir do Blue Book que seu emprego torna-se central na filosofia de Wittgenstein. Aqui não explicarei como o método torna-se central, mas apenas mostrarei que isso é o caso através de uma (rápida) análise das Cambridge Lectures de 1939 (WLC-39). 


\section{Tractatus: intensionalismo sistêmico e logicismo às avessas}

Wittgenstein tinha considerável interesse pela filosofia da matemática depois de sua volta a Cambridge em 1929, especialmente por problemas relacionados ao "infinito atual". É bem possível que este interesse tenha sido despertado por uma palestra dada por Brouwer em 1928, em Viena (ver Wittgenstein e o Círculo de Viena (WWK) p. 16). Um estudo comparativo entre o intuicionismo de Brouwer e Weyl e a filosofia de Wittgenstein pode ser, portanto, de grande interesse, principalmente por que estão de acordo quanto à não-atualidade do infinito. Contudo, tal investigação não pode tomar o lugar da investigação da filosofia da matemática de Wittgenstein e das razões internas que subjazem a seu desenvolvimento. Por mais interessantes que possíveis influências possam ter sido, elas não explicam por que Wittgenstein possa tê-las considerado relevantes para a dinâmica interna de seu pensamento.

Já no T, vale bem lembrar, o infinito dos números é dado por uma regra ou forma (intensionalmente) e o infinito atual (em extensão) não parece ter espaço. Números, no T, são expoentes de uma operação que pode ser reiterada indefinidamente (verT 6.01-031).Já no T Wittgenstein diz que, aparentemente contrário a uma das teses intuicionistas, uma suposta "intuição" (Anschauung), que poderia ser tomada como necessária para a solução de problemas matemáticos, "já é dada pela própria linguagem" (T 6.233). Tal "intuição" é, simplesmente, o "processo do calcular" (T 6.2331).

O Tractatus, a meu ver, tem duas teses fundamentais a respeito da natureza da matemática. Ambas são introduzidas para mostrar que as "proposições matemáticas" não são um contra-exemplo à forma geral da proposição (vale lembrar que o esboço da natureza dos números e proposições matemáticas é apresentado exatamente após a apresentação da forma geral da proposição). As proposições da matemática não são instâncias da forma geral da proposição (não são, portanto, proposições e nada descrevem), mas não são contra-sensos, pois sua correção é dada $a$ priori. As 2 teses explicam, de um lado, a natureza de proposições da matemática e, de outro, a natureza dos componentes fundamentais destas equações (os sinais numéricos). Eis as teses: 
1) A matemática (aritmética) é um método da lógica. Usamos as equações para fazermos inferências. A igualdade matemática indica uma regra de substituição inferencial.

2) A essência do número, a natureza fundamental de qualquer número, é dada pela forma geral da operação, "a forma mais geral de transição de uma proposição a outra" (6.01). Números são os expoentes desta operação. Existe, assim, um sistema numérico geral (mais sobre isto no que se segue).

"O conceito de número" (6.022) é a forma geral do número. Assim, o conceito de número é dado já com a série de números através de uma regra ou operação. ' 'Número' é, para Wittgenstein, um conceito formal e não um conceito real (como, digamos, 'gato') - ver 4.126. O que a forma geral da operação do número deixa claro é que a característica central dos números é a ordem. A ordem que se inicia com uma base $\mathrm{x}$ e desenvolvese como xO, xOO, xOOO..., na aplicação da operação, é a única característica essencial dada na definição dos números (ver T 6.02). Ela nos fornece os expoentes, que determinam a definição dos números cardinais $(0,0+1,0+2 \ldots)$. Assim, a determinação de uma quantidade numérica aparece como derivada e a idéia de classes como supérflua (6.031).

Isso nos leva ao logicismo às avessas de Wittgenstein no $T$. Na sua crítica ao formalismo, Frege diz que os formalistas estão errados ao dizer que os sinais matemáticos funcionam como as regras de um jogo, pois um jogo distingue-se essencialmente desses por terem sentido. Com esses sinais, diz Frege, expressamos pensamentos. Um apelo à aplicação da matemática não é viável aos formalistas. É somente o sentido das proposições matemáticas e, assim, o significado dos números, argumenta Frege, que garante a aplicação da mesma: "Por que não podemos fazer uma aplicação da posição de uma peça de xadrez? Evidentemente porque ela não expressa pensamento algum. Por que podemos fazer aplicações de equações matemáticas? Apenas porque elas expressam pensamentos." (Grundgesetze der Arithmetik (GG) II, (\$91). Russell argumenta de maneira semelhante em Introduction to Mathematical Philosophy. Quando trata das cinco proposições primitivas de Peano (0 é um número, o sucessor de qualquer número é um número, dois números não têm o mesmo sucessor, 0 não é o sucessor de nenhum número e o princípio de indução matemática), argumenta que existe "um número infinito de interpretações" (p. 7) que as satisfazem. Podemos, por exemplo, tomar "0" como 
100, ou entender "número" como "números pares"; ou tomar "0" como número 1 e sucessor como significando "metade" e formar a seqüência 1, 1 meio, 1 quarto, etc. Um número infinito de progressões, nos diz Russell, satisfaz os axiomas. Para ele, o remédio é definirmos "0", "número", "sucessor", e assim por diante. Como Frege, toma assim o caminho extensional: a relação 1-1 (similaridade) é dada em qualquer conjunto de objetos e é mais primitiva do que a noção de ordem (p. 17).

O remédio do $T$, no entanto, é entendermos que números não têm significado e que o caminho de definição é completamente intensional. Números são simplesmente o resultado de uma operação, isto é, são exatamente a ordem geral, não determinada, que Russell e Frege queriam determinar definitoriamente por meio de classes de classes. Essa ordem, para Wittgenstein, não é nem mesmo axiomática, pois é gerada por uma operação. Se temos o sistema dado com a aplicação ordenada da operação fundamental, temos a essência do número, que é simplesmente a ordem progressiva geral. Assim, o problema do significado dos números é, para Wittgenstein, fruto da recusa da aceitação da natureza absolutamente geral da essência numérica. Deste modo, Wittgenstein aceita uma relação essencial entre lógica e matemática (a última é um "método da lógica", pois o propósito de suas equações é o seu uso em inferências substitutivas), mas nega, ao mesmo tempo, a relevância de todo projeto definicional do logicismo: números são simplesmente os pontos do sistema de ordenamento progressivo universal infinito dado por uma regra ou operação fundamental.

A idéia de sistema já é fundamental no T: "Onde quer que se possa construir (bilden) sinais de acordo com um sistema, lá o sistema é aquilo que é logicamente relevante, e não os sinais individuais." (T 5.555). Isso vale tanto para a lógica quanto para a aritmética, pois existe um único sistema numérico: uma única regra nos dá a essência de qualquer número, aquilo que todos os números têm em comum. Em T 6.341, por exemplo, onde discute o "sistema da mecânica", Wittgenstein menciona "o sistema dos números".

Esse é um fato que não deve passar desapercebido, pois, como veremos, entre 1929 e 1933 (e mesmo depois) Wittgenstein desenvolve e defende a idéia de que existem vários sistemas independentes na matemática. Não sei o que exatamente o levou à idéia de diversos 
sistemas independentes e não vou especular a respeito aqui. Contudo, não pode haver nenhuma dúvida de que esta idéia é central no período. ${ }^{4}$

\section{Intensionalismo sistêmico em 1930 (MSS 105-8 e PB)}

Wittgenstein continua sendo um intensionalista em seu retorno à filosofia em 1929, pois em várias ocasiões diz aceitar o infinito somente em intensão (como propriedade de uma regra), e não em extensão (ver MS 105, ps. 23-7; MS 106 p. 36; PB \$144-5). Por exemplo, em uma aula no início de 1930, Wittgenstein diz: “A palavra 'todos' refere-se a uma extensão; mas é impossível referir-se a uma extensão infinita. Infinito é uma propriedade de uma regra, não de uma extensão" (Cambridge Lectures 1930-32, p. 13). Esta concepção não se aplica somente ao infinito numérico, mas também às demais formas (espaço e tempo, por exemplo, são dados por uma regra de construção - ver MS 106 p. 1 e PB $\int$ 143). Há, portanto, uma coincidência entre o intensionalismo de Wittgenstein na filosofia da matemática e o intensionalismo, digamos, fenomenológico. Isso não é estranho, pois existe também um paralelismo entre o verificacionismo fenomenológico e o matemático (mais a respeito na parte 3 ).

Como a citação acima atesta, Wittgenstein opõe o intensionalismo ao extensionalismo; nega, portanto, uma tese em filosofia da matemática por intermédio de outra tese. Está, portanto, em 1930, claramente distante da neutralidade que parece caracterizar sua filosofia tardia (prescrita pelo método genético). Isso pode ser constatado também nos desdobramentos da tese intensionalista, como veremos logo a seguir.

Uma característica fundamental da concepção extensionalista é a idéia de que as verdades matemáticas são dadas e que cabe ao matemático descobri-las. Supõe-se, por exemplo, que sempre existiram infinitos de diversos tamanhos e a Cantor coube simplesmente descobri-los. Os números, na concepção de Frege e Russell, são algo preciso e cabe ao filósofo descobrir a sua verdadeira essência. O filósofo descobre, por exemplo, que a relação de "similaridade" é uma relação que existe de antemão em conjuntos e determina a essência do número. Antes de Cantor, Russell e Frege, portanto, a matemática estava, por assim dizer, incompleta, pois supostamente havia uma série de verdades matemáticas 


\section{2}

que ainda não haviam sido descobertas a respeito da natureza do infinito ou a respeito da natureza do número.

À tese extensionalista de descobertas em matemática, Wittgenstein contrapõe a tese da completude da matemática e do sentido de qualquer proposição. ${ }^{5}$ Como diz Wittgenstein, "não existem pontos em aberto na matemática" (Wittgenstein und der Wiener Kreis, p. 35). No MS 108, p. 20 (PB S158), do mesmo mês, diz: "Não existem pontos em aberto em matemática. Isso contradiz a concepção usual." (ênfase minha). A razão para esta tese que "contradiz a concepção usual" é dada logo a seguir:

Matemática não pode ser incompleta; como o sentido não pode ser incompleto. Aquilo que posso compreender, preciso compreender completamente. (MS 108, p. 22)

Como no T (4.023 e 3.23), Wittgenstein defende a tese de que o sentido é completamente determinado. Ou uma proposição faz sentido ou não faz. O que subjaz a esta tese, aqui, é a idéia de que matemáticos, de acordo com Wittgenstein, não descobrem propriedades dos números ou do infinito, mas as inventam. (A idéia da existência de descobertas em matemática, por outro lado, obviamente assume a incompletude da matemática, pois não haveria nada a ser descoberto se a matemática fosse completa).

Contudo, a tese de Wittgenstein parece implicar que não poderia haver progresso ou ampliação do conhecimento em matemática. Se a matemática é completa, como explicar que ela se desenvolve e, aparentemente, se estende? A saída de Wittgenstein consiste em explicar tal progresso não como um processo cumulativo, mas como sendo a passagem de um 'sistema' matemático a outro.

A introdução dos números inteiros (negativos e positivos), por exemplo, é somente a invenção de um sistema matemático distinto. Não é, no entanto, a descoberta de um novo reino de números, tampouco uma extensão do sistema dos números naturais $(1,2,3 \ldots)$. Cada sistema é em si mesmo completo e simplesmente distinto dos sistemas anteriores.

Aqui, obviamente, poderíamos objetar que os números naturais são os mesmos em ambos os sistemas e que, portanto, a introdução dos negativos corresponde, sim, a uma extensão do sistema dos números naturais. A resposta wittgensteiniana é que cada proposição e cada elemento de um 
sistema não é o mesmo quando os sinais usados em um sistema continuam sendo usados no novo sistema. A aparência de que temos uma extensão do antigo sistema deve-se a certas relações entre ambos e à aparente preservação de certas propriedades. Parte do novo sistema, nos diz Wittgenstein, "tem a mesma estrutura do sistema antigo" (WWK p. 35-6). Wittgenstein, na passagem citada, esclarece o ponto com o exemplo dos números naturais e dos números inteiros. ${ }^{6}$ Os números naturais podem, por exemplo, ser colocados em uma relação 1 a 1 com os números inteiros positivos ( $1 \mathrm{com}+1,2 \mathrm{com}+2$, etc). A ordem (relações maior, menor, igual) no sistema de inteiros positivos também é preservada (+2 é maior do que +1 , assim como 2 é maior do que 1). Existe também um mapeamento das operações fundamentais nos dois sistemas (adição, substração, etc): $\mathrm{a}+\mathrm{b}=\mathrm{c}$ corresponde $\mathrm{a}(+\mathrm{a})+(+\mathrm{b})=(+\mathrm{c})$. Essas propriedades, no entanto, não mostram que existem propriedades comuns entre os números naturais e uma sub-classe dos números inteiros, os números inteiros positivos. Para Wittgenstein, temos aqui apenas uma espécie de projeção de parte do sistema antigo no novo. Na outra subclasse dos números inteiros, os negativos, o mapeamento das operações, por exemplo, não se aplica. Afora isso, o sistema de números inteiros tem também uma aplicação distinta da aplicação dos números naturais. Dizemos, por exemplo, "Três copos de cerveja estão sobre a mesa", mas não "+Três copos de cerveja estão sobre a mesa”. Esta última frase só seria caridosamente tomada como significativa se usada em um contexto em que contrastaria com "- Três copos de cerveja estão sobre a mesa” (isto é, quando estivesse tentando indicar que copos foram acrescentados ou retirados da mesa).

Em um novo sistema numérico, introduzimos novas regras e, assim, mudamos o significado dos antigos sinais: "O sistema de regras que determina o cálculo determina, desse modo, também o 'significado’ dos seus sinais...Assim, se mudo as regras - digamos, aparentemente as suplemento - então mudo a forma, o significado" (MS 105, p. 32; PB \$152). Os sentidos das proposições são, portanto, dependentes do sistema de que fazem parte: "entender p significa entender seu sistema. Se p aparentemente passa de um sistema a outro, então p, de fato, mudou seu sentido" (PB \$153). Para uma proposição "fazer parte de um sistema" significa "existir um método de prova" que a posicione dentro do sistema. Assim, é 
a prova matemática ou o método de prova em um sistema que dá sentido às proposições matemáticas e significado aos sinais (PB \$162).

Deste modo, sentenças matemáticas não podem fazer sentido se não existe um método de prova. "Só há um problema" matemático, diz Wittgenstein, “onde há um método de solução” (PB \$149). Portanto, fora de sistemas matemáticos com métodos de prova, um problema matemático e a 'sentença' matemática que dá resposta ao mesmo, não fazem sentido. Pseudo-sentenças matemáticas, sentenças fora de um sistema, são simplesmente contra-sensos. No caso dessas pseudo-sentenças não é somente o princípio do terceiro excluído ou os quantificadores que não se aplicam, mas todas as regras lógicas, pois não há propriamente uma sentença em questão (contrariamente a Brouwer e Weyl, de acordo com Wittgenstein (ver PB \$151)).

A idéia de diversos sistemas matemáticos tem duas conseqüências: uma positiva e uma, aparentemente, negativa. A conseqüência positiva é que, ao tomar a matemática como vários sistemas independentes, Wittgenstein parece fornecer um meio de explicarmos provas de impossibilidade em novos sistemas matemáticos. Por muito tempo vários geômetras euclideanos "queriam" trisectar o ângulo usando régua e compasso até que uma prova da impossibilidade da trisecção foi concebida. Tal prova só foi possível em um sistema que inclui álgebra e análise. ${ }^{7}$ Assim, a prova de impossibilidade mostra também que uma prova de trisecção ou impossibilidade de trisecção em geometria euclideana é também impossível. Qual é, então, o estatuto da afirmação “o ângulo pode ser trisectado com régua e compasso" em geometria euclideana? Se fazia sentido, como foi possível provar que a trisecção é impossível? Se aceitamos a concepção wittgensteiniana, podemos dizer simplesmente que não havia proposição alguma, pois uma tal 'proposição' não existe no sistema euclideano. A esse respeito, Wittgenstein diz:

A impossibilidade da construção [trisecção do ângulo] não pode ser compreendida no sistema de geometria elementar, mas, sim, no sistema dos números algebraicos e equações, no qual a geometria elementar é projetada. (WWK p. 36).

Desse modo, Wittgenstein pode enfatizar que somente o desenvolvimento da álgebra nos permite dar sentido à pergunta pela trisecção do ângu- 
lo. Antes a pergunta não fazia sentido, pois não havia um método dado no sistema de geometria elementar para dar qualquer resposta.

A conseqüência negativa do modelo wittgensteiniano, por outro lado, é que precisamos assumir que, por exemplo, a 'proposição' "Para qualquer número par $\mathrm{n}$ tal que $\mathrm{n}>2$, $\mathrm{n}$ é a soma de dois primos" (conjetura de Goldbach) é um contra-senso, pois não existe método de prova para esta conjectura. O mesmo vale para o "último teorema de Fermat" nos anos 30 (sobre Fermat ver PB $\$ \$ 149-50$ ). Isso é, obviamente, no mínimo, contra-intuitivo, não somente porque muitos matemáticos parecem crer que a conjectura de Goldbach é verdadeira, mas, mais importante, ela parece ser parcialmente confirmada por qualquer número que tomarmos como exemplo, mesmo que não possamos determinar que é esse o caso de todos os números. ${ }^{8}$

A concepção wittgensteiniana por volta de 1930 (nas PB) nos deixa, assim, com um problema: qual o estatuto dos 'problemas' matemáticos que estão fora de um sistema, ou seja, não estão ligados a um método de solução quando as instâncias parecem corroborar uma das sentenças ou equações que a respondem? Parece se seguir da concepção wittgensteiniana que eles são meros contra-sensos. Existe, ainda, um segundo problema ligado a esse: se o progresso ou desenvolvimento da matemática não consiste em descobertas, mas na invenção de novos sistemas, como é possível que um novo sistema seja inventado? Ou: o que torna possível a passagem de um sistema a outro mais complexo se não estendemos sistemas, mas apenas inventamos novos sistemas com a introdução de novas regras?

\section{Intensionalismo sistêmico no BT}

Esses problemas, acredito, encontram soluções mais plausíveis no BT. Primeiro, Wittgenstein assegura um papel aos pseudo-problemas: eles cumprem uma função em matemática, mesmo que não sejam 'problemas' reais. Eles não são considerados meros contra-sensos no BT, pois têm uma função em matemática. Sua função, no entanto, é completamente distinta da função dos problemas reais, aqueles que contam com um método de solução. A sua função é apenas direcionar a pesquisa matemática; eles 


\section{6}

são, por assim dizer, estímulos na investigação: “Uma proposição com uma prova pertence a uma categoria distinta de uma proposição sem uma prova. (Uma proposição matemática não provada - guia (Wegweiser) para a pesquisa matemática, estímulo (Anregung) para construções matemáticas)" (BT 631).

Essa solução, no entanto, parece colocar Wittgenstein em outra dificuldade: Wittgenstein parece não poder dizer que é a conjectura ela mesma que é provada pela nova prova. Se fosse, parece que transformaríamos uma proposição contingente em uma proposição necessária. Teríamos uma proposição que é contingentemente necessária, o que parece não ser necessidade alguma. De fato, Wittgenstein explicitamente nega que seja a conjectura aquilo que é, digamos, provado mais tarde. Antes da existência da prova, Wittgenstein diz,"a hipótese pode ser tomada como puramente física"; por outro lado, continua:

... se é fornecida uma prova, ela não prova em nada o que foi conjecturado, pois não posso conjecturar no infinito. Eu posso conjecturar apenas o que pode ser confirmado, mas através da experiência somente um número finito de conjecturas pode ser confirmado, e a respeito da prova não se pode conjecturar enquanto não se a tem, e então [quando se a tem] também não (BT 617; PG 359).

A razão para Wittgenstein, então, tomar a mesma frase como algo completamente distinto é a idéia de que enquanto hipótese ou conjectura ela tem um tipo de verificação e, enquanto parte de uma prova, um outro tipo de verificação (a verificação de uma sentença empírica e a verificação de uma sentença necessária). A frase antes e depois da prova tem uma generalidade distinta com métodos de verificação, como diz Wittgenstein, "essencialmente" distintos (BT 616-7; PG 360).

Essa solução wittgensteiniana é interessante por duas razões. Ela mostra que para dar um certo sentido a conjecturas matemáticas, Wittgenstein precisa lhes dar um conteúdo empírico. Wittgenstein diz, por exemplo, que quando se oferece um prêmio para a solução do teorema de Fermat, oferece-se "um prêmio pela solução de uma tarefa de ciência natural” (BT 619; PG 362).

A segunda razão para acharmos interessante a solução wittgensteiniana para o problema do conteúdo de conjecturas é que ela apresenta um novo 
problema, que indicará, por sua vez, o caminho para uma mudança na filosofia da matemática de Wittgenstein. Ele exemplifica a idéia do conteúdo empírico das conjecturas matemáticas através do exemplo de alguém que não teria provado o teorema de Pitágoras, mas tivesse chegado, por medições de catetos e hipotenusas, à conjectura da sentença pitagórica. Suponha, nos diz Wittgenstein, que o mesmo sujeito encontrasse a prova e dissesse que provou aquilo que tinha conjecturado. Wittgenstein não toma isso como um contra-exemplo à sua teoria, mas como uma espécie de confirmação da mesma. Ele retoricamente pergunta:

Em que ponto da prova aparece aquilo que anteriormente encontrava confirmado através dos experimentos? pois a prova é, contudo, essencialmente distinta do método anterior. - Onde tocam-se esses métodos, visto que, presumivelmente, resultam em algum sentido no mesmo [significado]? I.e.: Se a prova e os experimentos são apenas aspectos distintos do mesmo (da mesma generalidade). (BT 618; PG 360).

É claro que se a prova é essencialmente distinta dos experimentos, eles não se tocam ou não têm, digamos, nada em comum. Mas aqui Wittgenstein está simplesmente assumindo que existe uma distinção essencial. Está simplesmente negando que se possa dar suporte empírico (digamos, em um processo de tentativa e erro) e por meio de prova à mesma sentença. Poder-se-ia também pensar, contrário ao Wittgenstein do BT, que a frase empírica torna-se uma frase, digamos, necessária com a prova. Nesse caso, contudo, não é mais essencialmente distinta antes e depois da prova. De fato, Wittgenstein passará a distinguir sentenças que passam de empíricas a a priori de maneira menos dogmática: distinguem-se pela função, nos dirá mais tarde. No Yellow Book, por exemplo, Wittgenstein falará da "transição de uma hipótese a uma regra gramatical" (p. 70). Essa transição significa somente que quando é, digamos, inventada a prova, a confirmação por via de experimentos torna-se supérflua.

A idéia de que conjecturas não são contra-sensos nos leva diretamente à solução do segundo problema mencionado acima (o problema de como passamos de um sistema a outro). As conjecturas enquanto estímulos ou guias da pesquisa matemática podem nos ajudar a ver novos aspectos dos sistemas matemáticos em que operamos (BT 710-721). São como a formulação de “jogos e quebra-cabeças enigmáticos” (BT 721). Quando 


\section{8}

desvendamos um quebra-cabeça vemos algo antes não visto. Vemos um aspecto da linguagem ou do uso que fizemos de certos objetos. Pense, por exemplo, no seguinte quebra-cabeças ou enigma: construa quatro triângulos com quatro palitos de fósforo. ${ }^{9}$ Dado o problema, podemos passar uma tarde manipulando os palitos, conectando-os das mais diversas maneiras sem ver a solução. Podemos, inclusive, pensar que uma solução é impossível e tentar provar tal impossibilidade, como podemos provar a impossibilidade de certas combinações no xadrez (o xeque-mate com o rei e o cavalo é impossível, mas o xeque-mate com uma torre e o rei é possível, etc). Contudo, podemos também perceber que a solução do problema exige uma mudança de aspecto. Precisamos abandonar a idéia de que a solução deve ser dada em um espaço plano. Se usarmos os palitos tri-dimensionalmente, veremos que, se convergirem no vértice, formaremos quatro triângulos (em uma espécie de pirâmide de base quadrada). Neste exemplo, temos a invenção de uma nova maneira de manipular o simbolismo a partir de um aspecto visto. Ele é interessante porque mostra que não assumiríamos que a tri-dimensionalidade estava contida nos palitos ou dada em algum reino paralelo onde certas verdades existem antes de serem descobertas. Assim, aparentemente, ver aspectos não implica a incompletude do que analisamos.

Esses desenvolvimentos da filosofia da matemática de Wittgenstein no BT (1933) indicam uma reformulação da concepção intensionalista defendida em 1930 por intermédio da eliminação de algumas de suas conseqüências contra-intuitivas. O que Wittgenstein parece, então, fazer no BT é tornar uma tese filosófica mais plausível. Assim, Wittgenstein não parece estar de completo acordo com o seu lema nas Investigações Filosóficas (IF), onde diz que a filosofia, a sua, "não explica e não extrai nenhuma conseqüência” (IF \126). Ele mesmo, pelo menos no início da década de trinta, tinha uma tese explicativa com sérias conseqüências em filosfia da matemática, como vimos. Isso indica, pelo menos, que a filosofia da matemática do BT ainda não é determinada pelo método genético, o que está de acordo com minha hipótese interpretativa, segundo a qual é somente depois do BT que o método toma o centro do palco da filosofia de Wittgenstein. Existem, contudo, sinais de que a importância do método aumenta na filosofia da matemática de Wittgenstein depois de 1933? 


\section{Sobre a Filosofia da Matemática de Wittgenstein Depois de 1936}

Imediatamente depois de organizar o BT, Wittgenstein não escreve muito a respeito da filosofia da matemática. Volta a fazê-lo somente em 1937 (começa no MS 117). Neste manuscrito e em sua reformulação, que em 1937-8 era vista por Wittgenstein como a segunda parte das IF (publicada na parte I de Bemerkungen ueber die Grundlagen der Mathematik), encontramos claros sinais de uma nova abordagem da filosofia da matemática. Esta nova abordagem, creio, está em acordo com o método genético. Ela continua também presente nas aulas em Cambridge de 1939 (WLC-39). Utilizarei estas aulas para indicar como o método genético parece ser a característica central da filosofia da matemática de Wittgenstein no período tardio.

Como mencionei no início deste artigo, as características do método genético são as seguintes: 1) o interesse de Wittgenstein é investigar problemas filosóficos que são o produto de falsas analogias (imagens, símiles) e raciocínios enganosos; 2) a função de um filósofo (Wittgenstein) é indicar estas analogias e mostrar os raciocínios enganosos que geram problemas filosóficos; 3) o leitor pode, assim, ver suas próprias tendências como que em um espelho; 4) a investigação de Wittgenstein dever ser desenvolvida, então, em um nível pré-filosófico e neutro, pois não objetiva solucionar os problemas, mas dissolvê-los em sua gênese.

As quatro características do método genético parecem direcionar a filosofia da matemática de Wittgenstein apresentada em suas aulas. Em várias ocasiões (WLC-39 ps. 55, 95 e 103) Wittgenstein explicitamente diz que não quer nem mesmo apresentar opiniões filosóficas. $\mathrm{Na}$ sua primeira aula, por exemplo, diz: "Eu não vou dizer nada que alguém possa disputar. Ou se alguém disputar o que digo, eu vou abandonar o que disse e dizer algo distinto." (WLC-39 p. 22). Na quinta aula, Wittgenstein reinforça o ponto ao comentar uma frase de Lewis, que havia dito, depois de uma pergunta de Wittgenstein, "eu sei o que você quer que eu responda". O que Lewis disse foi tomado por Wittgenstein como "uma crítica severa". Wittgenstein explica:

Pois eu não tenho o direito de querer que você diga algo a não ser uma coisa: "Vamos ver" - Não se pode fazer uma formulação geral e dizer que eu tenho o direito de querer fazer você dizer isso. Pois o que 
poderia ser essa formulação geral? Minha opinião? Mas obviamente o ponto é que eu não posso ter opiniões... Por exemplo, eu não tenho o direito de querer que você diga que proposições da matemática são regras da gramática (WLC-39 p. 55).

Wittgenstein não pode ter opiniões porque tê-las contraria seu método. Até mesmo a opinião de que "proposições da matemática são regras da gramática”, que muitos comentadores pensam ser a característica mais importante da filosofia da matemática de Wittgenstein (por exemplo, Baker \& Hacker 1994, 2005a, 2005b, Glock 1996 e Forster 2004), não é algo que Wittgenstein não possa deixar de lado.

Manter a neutralidade prescrita pelo método genético é uma das grandes dificuldades presentes no ensinamento do mesmo, pois aquele que ouve Wittgenstein tem a tendência de atribuir-lhe concepções ou opiniões (como, de fato, fazem muitos de seus comentadores). Na décima primeira aula, Wittgenstein explicitamente aponta essa dificuldade e sua estratégia de não ter opiniões:

Uma das maiores dificuldades que eu encontro ao explicar o que tenho em mente é esta: vocês estão inclinados a expressar nossa diferença de um modo, como uma diferença de opinião. Mas eu não estou tentando persuadir vocês a mudar de opinião. Estou apenas recomendando um certo tipo de investigação. Se há alguma opinião envolvida, minha única opinião é que esse tipo de investigação é imensamente importante, e muito contrário a tendências de alguns de vocês. Se nestas aulas expresso alguma outra opinião, estou fazendo papel de palhaço. (WLC-39 p. 103)

Esta passagem, como as anteriores, demonstra a seriedade que Wittgenstein dá à completa abstenção de opiniões. O "tipo de investigação" que Wittgenstein quer recomendar é a investigação da gênese de problemas filosóficos. Em acordo com o método genético, a origem mais comum de confusões filosóficas deve-se a certas expressões da linguagem, a certos usos aparentemente análogos de certas expressões ou a certas imagens. Esse ponto é evidente em diversas passagens das aulas (por exemplo, WLC-39 ps. 15, 18, 142, 251). Uma delas é a seguinte:

Se eu digo que não existe tal coisa como a super-rigidez da lógica, o verdadeiro objetivo é explicar de onde a idéia de super-rigidez provém 
- mostrar que a idéia de super-rigidez não provém da mesma origem da idéia de rigidez. A idéia de rigidez é derivada da comparação de coisas como manteiga e elástico com coisas como ferro e aço. Mas a idéia de super-rigidez provém da interferência de duas imagens como a idéia da super-inexorabilidade da lei [A idéia em questão é a seguinte: um juiz pode aplicar ou não a lei, mas “a lei, ela mesma”, é inexorável ou super-rígida]. Primeiro temos: "A lei condena”, "O juiz condena". Daí somos levados, pelo uso paralelo de imagens, a um ponto em que estamos inclinados a usar o superlativo. Nós precisamos, então, mostrar as origens deste superlativo e que ele não provém da mesma origem da idéia ordinária (WCL-39, p. 199).

Se, contudo, é correta minha hipótese de que o método genético determina as características centrais da filosofia da matemática de Wittgenstein no final dos anos trinta, o que ocorre com a concepção intensionalista, que defendia no início dos anos trinta? Que tipo de papel, se algum, essa concepção pode ter na filosofia tardia de Wittgenstein? Creio que Wittgenstein usa a concepção intensionalista como uma concepção (uma interpretação) da filosofia da matemática a ser contraposta a outras concepções (por exemplo, ao realismo). No entanto, não a vê como uma concepção que queira defender: é apenas uma alternativa dialética a ser abandonada. Wittgenstein diz, por exemplo:

Produzirei, ocasionalmente, novas interpretações; não para sugerir que elas são corretas, mas para mostrar que a antiga interpretação e a nova são ambas arbitrárias. Eu vou somente inventar uma nova interpretação para colocá-la lado a lado com a antiga e dizer "Aqui, escolha, tome uma”. Eu apenas produzirei gás para expelir o gás antigo. (WLC-39 p. 14; meu itálico).

Aqui uma série de questões interessantes, das quais não posso tratar aqui, surgem. Se o intensionalismo é uma interpretação ou concepção entre outras ("gás para expelir o gás antigo”), como é que essa concepção opera no processo de esclarecimento da origem das questões filosóficas na matemática? $\mathrm{O}$ quanto são cogentes as elucidações da origem dos problemas filosóficos dadas por Wittgenstein em filosofia da matemática? Ou ainda, quais as conseqüências da filosofia da matemática quando nenhuma 
opinião filosófica é expressa? Outras questões relacionadas ao papel da filosofia da matemática na filosofia geral de Wittgenstein juntam-se às acima. Até 1939, a segunda parte das IF era a filosofia da matemática. Por que Wittgenstein decidiu abortar tal projeto? Existia uma insatisfação com a apresentação da filosofia da matemática? É possível que os objetivos da filosofia da matemática de Wittgenstein nunca tenham sido alcançados? Talvez não, e talvez tenha sido exatamente esse o motivo que tenha levado Wittgenstein a nunca publicar a segunda parte das IF. De qualquer forma, as perguntas aqui suscitadas indicam que estamos longe de ter elucidado a natureza e a importância da filosofia da matemática de Wittgenstein.

\section{A Philosophy of Mathematics em The Cambridge Companion to Wittgenstein.}

2 O método genético, inventado no início de 1931 (MSS 109-10), tem as seguintes características: a) suspeita de que problemas (questões) filosóficos são o produto de falsas analogias (imagens, símiles) e raciocínios enganosos (a suspeita diz respeito a linhas argumentativas utilizadas pelo próprio Wittgenstein); b) a função de um filósofo (Wittgenstein) é somente indicar estas analogias e mostrar os raciocínios enganosos que geram problemas filosóficos sem tomar partido em uma possível "solução"; c) o leitor pode, assim, ver suas próprias tendências como que em um espelho; d) a investigação de Wittgenstein deve ser desenvolvida, então, em um nível pré-filosófico e neutro, pois não objetiva solucionar os problemas, mas dissolvê-los em sua gênese. Faço um estudo detalhado deste método e de sua relação com o desenvolvimento da filosofia de Wittgenstein nos capítulos 3-6 da tese Wittgenstein on Grammar and Method (From 1929 to the Philosophical Investigations).

3 Isso é muito diferente, obviamente, do que faz Russell. Ele toma a noção de similaridade (correspondência) e a noção de classe como primitivos e, a partir disso, constrói classes de todas as classes similares, define então o número da classe como a classe de todos as classes similares a ela e, por fim, define cada número como aquilo que é o número de uma classe. A noção de quantidade é, portanto, central para Russell e não a noção de ordem.

4 No MS 106, p. 262, certamente anterior a julho de 1929, Wittgenstein ainda diz: "Os números precisam ser escritos, essencialmente, em (palavra "algum" riscada) um sistema. Isso condiciona sua essência” (ver também MS 105, p.55; 107, p. 38, 69). Em MS 107, p. 182 (aproximadamente setembro de 1929) Wittgenstein é explícito a respeito da existência de vários sistemas: “... deve ser mostrado que o desenvolvimento é infinito em cada sistema de números" (ver também MS 108, p. 153, onde fala de povos primitivos com um sistema completo do tipo $1,2,3,4,5$, muitos).

5 Com isso, indiretamente, Wittgenstein talvez oponha-se também a Brouwer, que escreve: "Intuicionismo... enfatiza a existência da matemática pura [como] independente da linguagem e no seu esforço de provar, com base nisso, a verdade da matemática construída até o momen- 
to, ele investiga em que medida os princípios lógicos ... podem ser usados - também na matemática do infinito - como um meio confiável prático de relacionar construções matemáticas puras." (Mathematics, Science and Language, p. 50).

${ }^{6}$ Waismann, que sigo aqui, desenvolve a idéia no capítulo 4 de Introduction to Mathematical Thinking.

${ }^{7}$ Ver Klein, F. Famous Problems of Elementary Geometry: The Duplication of the Cube, the Trisection of an Angle, the Quadrature of the Circle. Cosimo Classics, 2007 [1897].

8 Outra conseqüência estranha, da qual não tratarei aqui, é a seguinte: uma mesma sentença não pode ter duas provas distintas, dado que é a prova que dá significado à sentença.

${ }^{9}$ Este exemplo não é dado por Wittgenstein. A charada é apresentada por Bernard Weber Les Fourmis. Agradeço a Valerie Bubendorff por me colocar esta charada em um contexto nãowittgensteiniano

\section{Referências bibliográficas}

Baker, G. \& Hacker, P. M.S.: Wittgenstein: Meaning and Understanding (Part I Essays).Vol. 1 of an analytical commentary to the Philosophical Investigations. Second, extensively revised edition. Blackwel, 2005a.

,: Wittgenstein: Meaning and Understanding (Part II Exegesis: \$\$1184).Vol. 1 of an analytical commentary to the Philosophical Investigations. Second, extensively revised edition. Blackwel, 2005b. ,: Wittgenstein: Rules, Grammar and Necessity, Vol. 2 of an analytical commentary on the Philosophical Investigations. Blackwell, 1994.

Brouwer, L.E.J. Mathematics, Science and Language. In: From Brouwer to Hilbert. Mancoso, P. (org.). Oxford, 1998.

Forster, M. N.: Wittgenstein on the Arbitrariness of Grammar. Princeton and Oxford, Princeton University Press, 2004.

Frege, G.: Die Grundgesetze der Arithmetik I. Olms, 1963.

Gerard, S.: A Philosophy of Mathematics Between Two Camps. In; The Cambridge Companion to Wittgenstein. (Cambridge University Press, 1996); 171-97. Sluga, H. and Stern, D. G. (eds.).

Glock, H. J.: Necessity and Normativity. In: The Cambridge Companion to Wittgenstein pp.198-225. Cambridge University Press, 1996. 


\section{4}

Klein, F: Famous Problems of Elementary Geometry: The Duplication of the Cube, the Trisection of an Angle, the Quadrature of the Circle. Woodruff, B. and Smith, D.E. (tr.). Cosimo Classics, 2007 [1897].

Russell, B.: Introduction to Mathematical Philosophy. Routledge, 1998 [1920].

Weber, B. Les Fourmis. Librerie Générale Française, 1997.

Waismann, F. Introduction to Mathematical Thinking. Dover Publications, 2003.

Wittgenstein, L. Tractatus Logico-philosophicus. McGuiness B.F. and Pears, D. (trs.); Routledge, 2004.

, Philosophical Investigations. German-English edition. Anscombe, A. (tr.). Blackwell, 2001.

, Wittgenstein's Nachlass. The Bergen Electronic Edition. Oxford, 2000. , The Big Typescript. Nedo, M. (ed.). Zweitausendeins, 2000.

, The Big Typescript: TS 213. German-English Scholars' Edition.

Luckardt, C.G. and Aue, A.E. (eds. and trs.). Blackwell, 2005.

, Philosophische Bemerkungen. Werkausgabe Band 2. Suhrkamp, 1989.

, Wittgenstein und der Wiener Kreis. Werkausgabe Band 3.

Suhrkamp, 1993.

, The Blue and the Brown Books. Harper Torchbooks, 1960.

, Philosophische Grammatik. Werkausgabe Band 4. Suhrkamp, 1989.

, Bemerkungen ueber die Grundlagen der Mathematik. Werkausgabe

Band 6. Suhrkamp, 1999.

, Wittgenstein's Lectures Cambridge, 1930-32. From the notes of John King and Desmond Lee (ed.). University of Chicago Press, 1989.

, Wittgenstein's Lectures on the Foundations of Mathematics

Cambridge 1939. From the notes of Bosanquet, R.G., Malcolm, N., Rhees, R., and Smythies, Y. Diamond, C. (ed.). The University of Chicago Press, 1976. 